\title{
PEDAGOXÍA QUEER E EDUCACIÓN LINGÜIISTICA: UNHA APROXIMACIÓN A TRAVÉS DA REFLEXIÓN
}

\section{QUEER PEDAGOGY AND LANGUAGE EDUCATION: AN APPROACH THROUGH REFLECTION}

\author{
Daniel Amarelo ${ }^{2}$ \\ University of Colorado - Boulder
}

Resumo: Este traballo visa reflexionar sobre a integración na aula de lingua(s) dunha pedagoxía queer e emancipadora que cuestione a heteronormatividade e o binarismo sexo-xenérico. Ao longo destas páxinas, realizamos unha incursión pola teoría queer aplicada á docencia e contextualizada no sistema educativo da Galiza e propomos algunhas intervencións didácticas a modo de propostas performativas que poderían ser testadas no futuro. Presentamos esta aproximación como un ensaio que tenta incorporar ao ensino secundario unha forma de ser docente e de ser alumnx que se centre no fluído, na (procura da) pregunta máis do que na resposta clara e unívoca e na experimentación por medio do xogo lingüístico. Para iso, repasamos os principais fundamentos das pedagoxías queer en articulación coa lingüística e co ensino de linguas, para fecharmos con algunhas actividades posidentitarias para as aulas de galego/portugués.

Palabras-chave: Pedagoxía queer; Educación lingüística crítica; Sexualidade; Performatividade.

1 Este artigo nace no seo dun proxecto de investigación máis amplo acerca da integración de pedagoxías queer nas aulas de linguas e que foi levado a cabo na Galiza no ano académico 20192020. Quero agradecer ao profesorado do ensino secundario que participou no meu traballo de campo, cuxo labor diario é exemplo de esperanza e transgresión; á profesora Luz Zas Varela, da Universidade de Santiago de Compostela, pola excelente orientación; e ás dúas persoas revisoras anónimas, pois grazas ás súas suxestións o presente contributo mellorou inestimabelmente. Calquera erro ou omisión é da miña responsabilidade.

2 daniel.amarelo@colorado.edu 
Abstract: This paper presents a reflection on the integration of a queer and emancipatory pedagogy into language classrooms, aiming to question heteronormativity and the gender/sex binary. In these pages, we offer a journey through queer theory in its application to teaching in the Galician educational system, and we provide some didactic interventions from which to test performative pedagogical proposals in the future. We present this approach as an essay that attempts to incorporate into secondary education a way of being a teacher and being a student that focuses on the fluid, (the search for) questions more than clear and unambiguous answers, and experimentation through language play. To do this, we review the main foundations of queer pedagogies in articulation with linguistics and language teaching, ending with some post-identitarian activities for Galician and Portuguese language classes.

Keywords: Queer Pedagogy; Critical Language Education; Sexuality; Performativity.

\section{INTRODUCIÓN}

Este traballo que aquí presentamos, tanto en termos teóricos como en termos loxísticos, naceu torto, o que se chamou hai algún tempo en inglés queer - palabra cun significado próximo de 'estraño' e posteriormente usada para atacar as persoas homosexuais, primeiro, e para subverter o seu significado orixinal e reapropiarse parodicamente del por parte das persoas non heterosexuais, despois. Na actualidade coñecémola polo uso académico que, desde espazos anglófonos, nos foi contaxiando aos poucos baixo ese rótulo desconfiante de "teorías queer". O presente estudo, inicialmente pensado para realizar un labor etnográfico, sufriu mudanzas na estrutura e no deseño que o tornan queer non só na temática mais tamén no propio proceso de confección. A copresenza co alumnado de secundaria e o ensaio empírico e corporal que nos permitiría servir de base para o proxecto inicial esvaecéronse coa chegada da situación socio-sanitaria causada pola COVID-19, que fixo que permanecésemos confinadxs nas nosas casas - quen temos a posibilidade de termos unha vivenda digna- durante semanas. No entanto, a pertinencia do traballo e algunhas das preguntas básicas que pretende responder están aínda vixentes. É posíbel ensinar lingua(s) desde unha perspectiva non heterosexista reforzadora da heterosexualidade como norma e do machismo como inercia? Como? Que recursos podemos ter en conta e que estratexias podemos 
implementar para evitar unha educación lingüística sexualmente aséptica? Que espazo cabe para as sexualidades diversas? Como crear comunidades discursivas queer que nos permitan crear novos mundos e identidades sen caermos en esencialismos? Como veremos, a interrogación é un exercicio constante nas pedagoxías queer nas cales nos adentramos a continuación.

O obxectivo xeral é a tentativa de subverter a escola como unha das axencias principais de normalización social en que se reproducen e organizan as identidades de maneira xerárquica en termos de raza, xénero e sexualidade (MOITA LOPES, 2008, p. 127). Por iso, os piares que sustentan a proposta, e a posición do propio pesquisador a respecto do traballo, fundaméntanse nunha implicación corporal e cualitativa a respecto da non-normalidade no escenario pedagóxico. Nesta dirección, quixemos contribuír cun pequeno chanzo que permita que no futuro construamos aulas máis xustas e emancipadoras en que a única norma sexa a diferenza. Diferenza intrínseca e non fetichizada en tempos de neoliberalismo salvaxe: toda diferenza pode ser integrada de modo retórico sen cuestionar o sistema que fundamenta o que nos torna a algunhxs como diferentes a respecto da norma. É xusto recoñecer que este espazo de cuestionamento desde a investigación educativa bebe dun labor continuado nos últimos tempos, se ben que reducido (MENARD-WARWICK; MORI; WILLIAMS, 2017, p. 486).

Sabemos que, no Estado español, un $43 \%$ das persoas LGBTIQ que sufriron acoso no centro de ensino valorou a hipótese do suicidio, 35\% concretizou plans para iso e $17 \%$ tentou realizalo, triplicando a porcentaxe de intentos de suicidio entre suxeitos que tiñan sufrido acoso en xeral (Federación Estatal de Lesbianas, Gais, Transexuales y Bisexuales, apud DEPALMA, 2017, p. 1). Pola súa banda, os resultados do informe da Axencia para os Dereitos Fundamentais (FRA) da Unión Europea (FRA, 2020a; 2020b) recollen as seguintes informacións: unha en cada dez persoas LGBTIQ foi vítima dun 
ataque físico nos últimos cincos anos na UE e un 47\% sentiuse discriminado ou agredido nos últimos doce meses por causa da súa orientación (38\% no caso español), para alén do dato simbólico de que un $60 \%$ evita ir da man coa súa parella pola rúa. O 21\% das lésbicas e o 19\% dos gays sentiron discriminación no contexto laboral; no caso de persoas intersexuais e trans, aumentan até 32 e $36 \%$. Na escola, polo menos unha persoa terá apoiado alumnxs LGBTIQ entre 15 e 17 anos en case a metade dos casos, mais, aínda hoxe, un 43\% afirma ter sido ridiculizado, insultado ou ameazado no espazo educativo (particularmente, un $49 \%$ denuncia ter sufrido acoso no caso concreto de España e un $26 \%$ de persoas entre 15 e 17 anos esconde a súa orientación). Igualmente, sobre un terzo das persoas inquiridas asegura ter visto ou ouvido condutas e comentarios negativos sempre ou con frecuencia por causa de teren percibido un colega como LGBTIQ ao longo da súa traxectoria escolar antes dos 18 anos. Con este panorama que, para alén das estatísticas, é fácil vivenciar nos centros de ensino cada día, xorde a pregunta de cal pode e/ou debe ser o noso papel en canto docentes e de cal é a postura e a acción das administracións.

\section{PEDAGOXÍAS QUEER: TIRANDO AUCTORITAS Á ESCOLA}

As pedagoxías queer desbordan o concepto dun marco teórico e non poden ser definidas nin clasificadas estática e sistematicamente pois non existen de maneira unívoca e fechada. A súa propia denominación en plural e as súas plurais denominacións - pedagoxías críticas, engaxadas, transformadoras, antiautoritarias, pos-identitarias, transgresoras, emancipadoras, críticas, encarnadas, subversivas, bastardas, trans* etc. - dan unha imaxe ecléctica e líquida. Mais podería ser un punto de consenso inicial, desde o cal comprender mellor o proxecto que encarnan, a idea de que o que une toda esta diversidade é o feito de incorporaren "os saberes dos movementos sociais e as ciencias sociais que abordan as críticas feministas, mais tamén desde o antirracismo, teorías 
críticas coa diversidade funcional e a sexualidade, descoloniais e sobre a xustiza social"3 e, ao mesmo tempo, o feito de cuestionaren "que os coñecementos e prácticas máis comúns sexan neutros e obxectivos, que sexan ahistóricos ou universais" ${ }^{4}$ (PLATERO, 2018, p. 27). Porén, en coherencia cos seus postulados éticos e coas súas pretensións políticas, será necesario percorrer a obra de teóricas que, desde espazos socioculturais diversos e distantes (aínda que, sobre todo, anglófonos), teñen pensado a práctica docente en paralelo - ou, nunha expresión menos straight, en cruzamento - con outras áreas do coñecemento e da existencia corporal. A máis destacada é a das teorías queer que, desde os anos 90 e na trilla de pensadoras como Judith Butler (2006 [2004]; 2007[1990]), Eve Kosofsky Sedgwick (2003 [1990]) ou Teresa de Lauretis, traballan as identidades como construcións culturais mediadas polo poder, incluíndo aí nocións tradicionalmente fixas como muller ou homosexual. Neste escenario, estes dous termos son categorías artificiais que creamos ao socializarmos de acordo a tendencias e dispositivos de control: serei muller ou home porque, desde que o médico declarou "é neno/nena", os xestos lingüísticos, estéticos e educativos me construíron en coherencia coa feminidade ou masculinidade normativa. A escola, obviamente, é un deses dispositivos.

Se hai algo común nestas formulacións teórico-corporais que nos permiten falar de pedagoxías queer é a formulación de preguntas máis do que a afirmación de solucións fechadas. Susanne Luhmann comeza a súa incursión polo campo da maneira máis coherente con esta posición ética, facendo unha morea de preguntas que, desde a interrogación metodolóxica, epistémica, teórica e práctica, desestabilizan a propia idea dunha pedagoxía queer definíbel

3 Todas as traducións para o galego de orixinais en linguas estranxeiras son da nosa autoría. "los saberes de los movimientos sociales y las ciencias sociales que abordan las críticas feministas, pero también desde el antirracismo, teorías críticas con la diversidad funcional y la sexualidad, decoloniales y sobre la justicia social"

4 "que los conocimientos y prácticas más comunes sean neutros y objetivos, que sean ahistóricos o universales" 
e fechada. Ao final, como indica máis adiante, o primeiro paso para comprender(se) este modelo é o feito de a pedagoxía queer aprender a ser autoreflexiva:

Como se pode imaxinar unha pedagoxía queer? Até o momento, non está claro como semellaría esa tal pedagoxía ou para quen sería esa pedagoxía queer. Cales serían as súas ambicións, e onde tería lugar? É unha pedagoxía queer sobre e para alumnado queer ou profesorado queer? Unha pedagoxía queer é unha cuestión de currículo queer? Ou é sobre métodos de ensino adecuados para contido queer? Alén diso, vai a pedagoxía queer tornarse a leira pedagóxica dos estudos queer ou é acerca da queerización da teoría pedagóxica?5 (LUHMANN, 1998, s/p)

Ademais, segundo esta autora, esta proposta atenta contra o propio coñecemento xa que troca as estratexias de transmisión polo inquérito ou interrogación das condicións en que se comprende, ou mesmo refuga, o coñecemento (LUHMANN, 1998, s/p). E faino nun campo institucionalizado historicamente como é a pedagoxía, cuxa referencia ás normas é unha característica común (PLANELLA; PIE, 2012, p. 275).

Pola súa banda, podemos considerar o texto "La pedagogía transgresora y sus extrañas técnicas" (BRITZMAN, 2002) un dos elementos fundadores da pedagoxía queer. Alí, a súa autora recolle algúns interrogantes, como é habitual neste campo, para elaborar as súas consideracións posteriores. Un deles é o de como podería desenvolver a pedagoxía un pensamento sobre a ausencia da normalidade (BRITZMAN, 2002, p. 198). Nesta liña, concibe unha pedagoxía que entrañe risco, incerteza e compromiso en momentos traumáticos como

5 "How can one imagine a queer pedagogy? As of yet, it is unclear what such a pedagogy might look like or for whom this queer pedagogy would be. What would be its ambitions, and where would it take place? Is a queer pedagogy about and for queer students or queer teachers? Is a queer pedagogy a question of queer curriculum? Or, is it about teaching methods adequate for queer content? Or, about queer learning and teaching-and what would that mean? Moreover, is a queer pedagogy to become the house pedagogy of queer studies or is it about the queering of pedagogical theory?" 
piares ou fundamentos (BRITZMAN, 2002, p. 200) da vida social e escolar. Afirma máis adiante que

Cando a pedagoxía coincide coa teoría queer e se preocupa pola súa propia estrutura de intelixibilidade - coa educación da educación- e cando a pedagoxía se enfronta á súa propia impertinencia, o propio proxecto do coñecemento e do suxeito que presumibelmente sabe convértense en tarefas interminábeis malia a presión institucional para se cumpriren a norma, a orde e a certeza ${ }^{6}$. (BRITZMAN, 2002, p. 204)

Unha das ideas principais do proxecto da pedagoxía queer que pode axudar a explicar este modelo en continua (de)construción é a quebra de binomios socialmente asumidos como estancos e irrefutábeis. De entre eles, destaca o de coñecemento/ignorancia, que se pretende desmontar desde a caixa de ferramentas do queer, precisamente levando o cuestionamento deste tipo de teorías para a práctica educativa e unha vez recoñecida a ignorancia como produto dun modo concreto de coñecemento (FLORES, 2008, p. 18). A ignorancia non é o oposto do coñecemento, senón que o constitúe dialogando con el, producida por un tipo particular de coñecemento ou de modo de coñecer (LOPES LOURO, 2001, p. 551). Ignorar, por exemplo, aquelas identidades de xénero disidentes que non encaixan no binomio home/muller ou aquelas sexualidades non normativas (isto é, non hetero) baséase nun tipo de relación epistémica con elas que as veta e afasta, implicando o propio axente que "ignora". Britzman, pola súa banda, define a ignorancia como un efecto, e non unha ausencia, de coñecemento; o que podería levarnos a pensar a ignorancia acerca da homosexualidade como ignorancia sobre como se constrúe a heterosexualidade (BRITZMAN, 2016, p. 61). É neste contexto onde, contrariamente ao modelo de visibilización das "minorías sexuais", as

6 "Cuando la pedagogía coincide con la teoría queer y se preocupa por su propia estructura de inteligibilidad - con la educación de la educación - y cuando la pedagogía se enfrenta a su propia impertinencia, el proyecto mismo del conocimiento y del sujeto que presumiblemente sabe se convierten en tareas interminables a pesar de la presión institucional para que se cumplan la norma, el orden y la certeza." 
pedagoxías queer ou transgresoras apostan por analizaren criticamente como funciona, tamén, a heterosexualidade e a heteronormatividade nun escenario de privatización da sexualidade (disidente) e normalización da heterosexualidade como algo (i) que é inherente e natural até o punto de rozar a súa inexistencia para os suxeitos (FRANCISCO, AGUIRRE; MOLINER, 2018) e (ii) que non ten nada que ver coa homosexualidade e outras formas de desexo e identidade non normativas (BRITZMAN, 2016, p. 47). En palabras de val flores:

A ignorancia é un efecto dun modo de coñecer, polo cal coñecemento e ignorancia están mutuamente implicados. A ignorancia como política do coñecemento é a forma que adquire a heterosexualización do saber, que promove o des-coñecemento acerca das sexualidades non normativas. A ignorancia constitúese así nunha "forma" de coñecer, unha especie de "residuo" do coñecemento. Esta operación política e epistemolóxica exíxenos entender que toda aprendizaxe é tamén unha desaprendizaxe de certo coñecemento ${ }^{7}$. (FLORES, 2016, p. 20)

Isto implica que as pedagoxías queer se constrúan como un modelo crítico co multiculturalismo liberal da escola contemporánea, ao que se lle apón a fetichización da inclusión de minorías consideradas exemplos de diversidade, sen cuestionar os antagonismos sociais inherentes (HOOKS, 1994, p. 31; LOPES LOURO, 2001, p. 550). Prestan atención aos procesos de mercantilización das loitas sociais como o feminismo ou o antirracismo (HOOKS, 1994, p. 71), da mesma forma que coa diversidade sexual e a súa emancipación e socialización, politizando estas cuestións en espazos como as salas de aula. Por tanto, non se ensina un catálogo de identidades estrañas que se traen á sala de aula como inclusión de rarezas, senón que se procura "desaprender as formas

7 "La ignorancia es un efecto de un modo de conocer, por lo cual conocimiento e ignorancia están mutuamente implicados. La ignorancia como política de conocimiento es la forma que adquiere la heterosexualización del saber, que promueve el des-conocimiento acerca de las sexualidades no normativas. La ignorancia se constituye así en una "forma" de conocer, una especie de "residuo" del conocimiento. Esta operación política y epistemológica nos exige entender que todo aprendizaje es también un desaprendizaje de cierto conocimiento." 
heterosexualizadas do pensar, ollar, sentir e interrogar"8 en articulación coa loita contra as opresións raciais, de clase, de normalidade corporal e outras "coordenadas de desigualdade social, visual e erótica"9 (FLORES, 2016, p. 28). Refuga a política da inclusión e da tolerancia porque reproduce a violencia e a discriminación que pretende erradicar ao recoñecer que hai un outro, ilexítimo e abxecto, que se inclúe nun marco de normalidade inherentemente lexítima (LOPES LOURO, 2000, s/p). Ou, en palabras de Wendy Brown:

A antipatía, a desaprobación e a regulamentación espreitan no corazón da tolerancia. Tolerar non é afirmar, mais permitir condicionalmente o que é indesexado ou desviante. E, embora presentada como alternativa á violencia, a tolerancia pode desempeñar un papel na xustificación da violencia... Chea de normas e consolidando a dominación por parte dos poderosos, a tolerancia sustenta a abxección dos tolerados e equipara os intolerantes aos bárbaros. ${ }^{10}$ (apud KJARAN, 2017, p. 182)

Ao fío do cuestionamento do que é e de como funciona a ignorancia, Britzman comenta o estraño paradoxo / o paradoxo queer de que as identidades emerxentes (como lésbica, gay ou outras formas de amar e sentirse) se tornen máis visíbeis e, mesmo así, menos comprendidas (BRITZMAN, 2016, p. 53-4). A inclusión de máis imaxes e informacións sobre o que é periférico nun determinado mercado das identidades, en efecto, non funciona. Porque o mero fornecemento de información non abonda para neutralizar a ignorancia cando esta opera como un modo de coñecemento que mantén resgardado o que xa se sabe e que, neste sentido, forma parte dos suxeitos (BRITZMAN, 2002, p. 213;

"desaprender las formas heterosexualizadas del pensar, mirar, sentir e interrogar."

"coordenadas de desigualdad social, visual y erótica"

10 "Dislike, disapproval, and regulation lurk at the heart of tolerance. To tolerate is not to affirm but to conditionally allow what is unwanted or deviant. And, although presented as an alternative to violence, tolerance can play a part in justifying violence ... Heavy with norms and consolidating the dominance of the powerful, tolerance sustains the abjection of the tolerated and equates the intolerant with the barbaric." 
FLORES, 2006, p. 20). Embora o sistema considere a LGBTIQfobia ${ }^{11}$ como un problema de representación causado pola ausencia de imaxes (positivas) de gays, lésbicas ou trans* (TRUJILLO, 2015, p. 1435), a pedagoxía emancipadora teima en facer as cousas dun modo distinto e desconforme con esta idea porque xa se ten mostrado insuficiente.

É común sinalar neste modelo a énfase e o traballo continuado en facer ver que a heterosexualidade tamén é unha identidade construída. Non só as chamadas minorías sexuais, senón o propio padrón de normalidade é socialmente construído. Andrea Francisco Amat e outrxs indican, nun artigo ilustrativamente titulado "Heterosexual, ¿qué es eso?...", que un 22\% da súa mostra de estudantado de ESO non sabe o que significa "heterosexual" e que un $35,6 \%$ considera a construción da sexualidade como algo innato ou natural, desenvolvido desde a infancia (FRANCISCO, AGUIRRE; MOLINER, 2018, p. 99). A urxencia dunha reorientación do modelo á luz destas informacións é evidente, especialmente para os espazos físicos e discursivos dos centros de ensino en que xs xoves interaxen desde posicións de xénero moi marcadas e experimentan as posibilidades da sexualidade.

En canto á praxe das pedagoxías queer, enténdese a aula como unha comunidade en que temos capacidades para crear excitación e interese ouvindo as voces e recoñecendo a presenza dxs outrxs (HOOKS, 1994, p. 8). Relacional e emocionalmente, visan quebrar o binomio teoría/práctica aproximando a teorización da experiencia (HOOKS, 1994, p. 61) e usan a sala de aula como unha plataforma para crear un "queer counterpublic" (KJARAN, 2017, p. 193) ou comunidade de práctica disidente en que poidan formarse novas identidades e visións do mundo.

11 Aversión, discriminación e violencia, nas súas distintas formas, cara ás persoas lésbicas, gays, bisexuais, trans, intersexuais e queer. 
En definitiva, unha pedagoxía queer liberta non só o alumnado mais tamén o profesorado, sabendo que “a presunción xeral de heterosexualidade, que identificamos noutro lugar como unha manifestación primaria do heterosexismo (...), funciona como unha tecnoloxía do eu na produción e policiamento de identidades docentes"12 (EPSTEIN; JOHNSON, 1998, p. 146). Como indica Deborah Britzman, "o neno" de calquera pedagoxía - ao que poderíamos engadir, talvez, "o profesor" de calquera pedagoxía- xa está codificado como un neno normalizado en termos de xénero, sexo e raza e tórnase, así, nun dos constructos máis normalizados e regulados en educación (BRITZMAN, 2016, p. 43-4). Algunhas autoras sinalan núcleos conceptuais dentro desta pedagoxía que poderían servir de trabes para o deseño e comprensión de prácticas educativas queer, como a que proporemos neste traballo para materias da área de linguas, como a deconstrución do carácter natural das identidades sexuais, o rexeitamento da heteronormatividade, a quebra co binomio normal-anormal e a fisura e desestabilización dos limites da(s) identidade(s) (CARRERA, CID; LAMEIRAS, 2018, p. 62). Aspectos, todos eles, que guían a nosa proposta final.

\section{A LINGÜÍSTICA QUEER COMO FERRAMENTA INTERROGATIVA}

Acabamos de estabelecer algúns principios para a comprensión das pedagoxías queer e para o futuro traballo real desde elas. Neste camiño, antes de chegar ao contexto empírico das aulas de lingua(s), hai que trasladar ou traducir o proxecto pedagóxico recentemente esbozado para a educación lingüística. A pedra que encontramos no camiño, que nos fai demorar, rodear e repensar(nos) é a chamada Lingüística Queer (doravante, LQ). Malia que poida

12 "the general presumption of heterosexuality, which we have identified elsewhere as a primary manifestation of heterosexism (...), works as a technology of the self in the production and policing of teacher identities" 
parecer un enredo un bocado brusco neste traxecto, é preciso parar neste punto e tentar indagar sobre esta corrente. Porque cando unhx docente de lingua ensina análise sintáctica, relacións semánticas, contextos e tendencias sociolingüísticas ou uso de estratexias pragmáticas en artigos xornalísticos, entre outras cuestións, faino desde os estudos que, nun punto ou outro da súa vida, protagonizou. Así, a socialización e aceptación xeral dun marco funcionalista e dunha compartición estanca das disciplinas tivo e continúa a ter unha pegada nas aulas das materias lingüísticas en que, por exemplo, podería haber discordancias entre o profesorado de lingua galega e o de lingua castelá, ou o de lingua inglesa e latín ${ }^{13}$. Para contextualizar a nosa intervención, cómpre entón desvendar que propón a LQ.

$\mathrm{Na}$ xenealoxía dunha comprensión da lingua como elemento de construción da realidade, a lingüística feminista gañou espazos académicos e sociais durante as décadas de setenta e oitenta, grazas ás obras institucionalizadoras de teóricas como Robin Lakoff (1975) ou Deborah Tannen (1990). Na aproximación pos-estruturalista aos fenómenos lingüísticos, hoxe relativamente imperante, o afortunado encontro entre feminismo e linguaxe contou con outros elementos que acompañaron a viaxe, como os estudos gays e lésbicos (v. gr., LEAP, 1996). Outras visións da lingua xurdían no final do pasado século para comprender como funciona a comunicación se analizada cos lentes do xénero e da sexualidade. Propiamente, a LQ nace como tal co libro Queerly Phrased de Anna Livia e Kira Hall (1997), en cuxa introdución destacan a integración da teoría queer na investigación lingüística a través, especialmente, do concepto "performatividade" inicialmente teorizado polo pragmatista John Austin e desenvolvido máis tarde por Judith Butler con atención á identidade

13 Porén, nos últimos tempos a proposta coñecida como Tratamento Integrado de Linguas (vid., inter alia, APRAIZ JAIO; PÉREZ GÓMEZ; RUIZ PÉREZ, 2012) axuda a minimizar esta problemática, herdeira de dinámicas ben asentadas de lexislación, formación e acomodación do profesorado. Agradezo a unha das persoas revisoras a suxestión deste punto. 
de xénero (BUTLER, 2004). En liña coas ideas críticas coas políticas de identidade que comentamos para a pedagoxía, tamén para os usos e prácticas lingüísticas funcionarían o xénero e a sexualidade como construcións e negociacións discursivas. Non se trataba xa de ligar determinadas categorías sexo-xenéricas (muller ou gay, por exemplo) cun catálogo de trazos lingüísticos - lexicais, morfolóxicos, fonéticos ou pragmáticos - fechados, senón que esas características e actuacións serían empregadas polxs falantes de maneira performativa. Isto é, non existiría unha ligazón directa e unívoca: os recursos dependen do contexto e úsanse diversa e creativamente para negociar sentidos e identidades. Polo tanto, a investigación lingüística queer non procura unha linguaxe lésbica, gay ou feminina e si "o espaço semântico-pragmático entre os discursos dominantes (i.e. heteronormatividade) e a performance linguística situada" (BORBA, 2015, p. 94). Así, será posíbel estudar "como fenômenos macro-sociológicos (...) produzem certos indivíduos como seres abjetos, inferiores ou patológicos" con base "nos detalhes mais ínfimos de nossa vida social, notadamente, a linguagem-em-uso" (BORBA, 2015, p. 94). Nunha combinación entre o micro e o macro, a disciplina pretende investigar as relacións entre linguaxe e heterosexualidade normativa (BENGOECHEA, 2015, p. 221) e non entre linguaxe e condición ou orientación sexual estanca. Con base na análise crítica da heteronormatividade, definida por Cameron como

o sistema que prescribe, ordena, recompensa e naturaliza un tipo particular de heterosexualidade - monogámica, reprodutiva e baseada en papeis de xénero convencionalmente complementares - como a normal na cal deben estar baseados os acordos sociais ${ }^{14}$ (CAMERON, 2005, p. 489),

este campo tense mostrado frutífero en distintas xeografías culturais e académicas (SANTOS FILHO, 2015; MOITA LOPES, 2006; 2008; CAMERON;

14 "the system which prescribes, enjoins, rewards, and naturalizes a particular kind of heterosexuality - monogamous, reproductive, and based on conventionally complementary gender roles - as the norm on which social arrangements should be based" 
KULICK, 2003; EHRLICH, MEYERHOFF; HOLMES, 2017; GRECO, 2012;

MILANI, 2013).

Para o noso caso particular, parece conveniente tentar integrar nas aulas do ensino medio esta perspectiva sobre a lingua como unha práctica social en que as nosas concepcións, identidades e ámbitos están constantemente en xogo e negociación. Unha hipótese de pesquisa é, por exemplo, como se sobreenfatizan aspectos lingüísticos "masculinos" ou "femininos" para ligar ou como os insultos que se usan están determinados por relacións de xénero e sexualidade lexicalmente marcadas. Antes de pasar para a ligazón entre sexualidade e linguaxe xa no eido pedagóxico, cómpre ter en conta que a separación entre normalidade e anormalidade é construída, deconstruída e reconstruída discursivamente por medio da linguaxe (PLANELLA; PIE, 2012, p. 269-70). Ou, como indica val flores:

Hai palabras que resultan -aínda- imposíbeis de escribir en cadros e cadernos escolares. Palabras que manchan, que lixan, que contaxian, que non soamente son impronunciábeis mais tamén in-escribíbeis. Palabras esganadas polas leis da civilización, a moral, a normalidade, a "boa educación".

As prácticas pedagóxicas son prácticas de fala, convocan unha arte da palabra nun oficio de relación, que nos configuran como suxeitos na medida en que demarcan que é o que se pode dicir, con que palabras podemos ser nomeadxs, articulando o que fica dentro e fora da linguaxe compartillada ${ }^{15}$. (FLORES, 2016, p. 27)

A lingüística queer, por tanto, pode funcionar de elo entre a socialización e instrución lingüísticas e a práctica pedagóxica nun sentido global e nunha

15 "Hay palabras que resultan -todavía- imposibles de escribir en pizarrones y cuadernos escolares. Palabras que manchan, que ensucian, que contagian, que no tan sólo son impronunciables sino también in-escribibles. Palabras estranguladas por las leyes de la civilización, la moral, la normalidad, la "buena educación".

Las prácticas pedagógicas son prácticas del habla, convocan un arte de la palabra en un oficio de relación, que nos configuran como sujetos en la medida en que demarca qué es lo que se puede decir, con qué palabras se nos puede nombrar, articulando lo que queda dentro y fuera del lenguaje compartido." 
dirección práctica e desesencializadora, xa que "entendida a LQ como centrada na desconstrución analítico-discursiva da heteronormatividade, a súa aplicación no ámbito educativo derívase dos presupostos e formulacións da pedagoxía queer"16 (MORENO SÁNCHEZ, 2019, p. 57).

\section{UNHA EDUCACIÓN LINGÜÍSTICA INTEGRADA: XÉNERO, SEXUALIDADE, DIVERSIDADE}

Se atendermos ao currículo oficial das materias de Lingua Galega e Literatura e Portugués no ensino secundario da Galiza (XUNTA DE GALICIA, s/d), observaremos unha división en bloques de contido maioritariamente centrados en aspectos lingüísticos e comunicativos. Dado este enorme peso curricular, especificado e subdividido profundamente, as cuestións de xénero, sexualidade e diversidade non só son inherentes senón que tamén poden ser intersticiais e servir de unión para tratar a complexidade de fenómenos discursivos, comunicativos e culturais que permean as referidas materias. Consideramos, con base nos escritos de múltiples docentes e teóricxs, que a única educación lingüística efectiva e de calidade que vele por algúns dos aspectos indicados nese currículo será aquela que garanta un rendemento escolar positivo e equitativo, algo que só e posíbel erradicando o ambiente escolar discriminador e normativo. Pois existe unha ligazón constitutiva entre a distribución do éxito/fracaso e as identidades e xerarquías codificadas no espazo escolar (JUNQUEIRA, 2013, p. 494). A heteronormatividade, a LGBTIQfobia e o machismo, por tanto, poñen en causa a calidade da formación do alumnado incluíndo, con forza e particularmente, a súa formación en linguas.

16 "entendida la LQ como centrada en la deconstrucción analítico-discursiva de la heteronormatividad, su aplicación en el ámbito educativo se deriva de los presupuestos y planteamientos de la pedagogía queer" 
Por iso, fronte ás pedagoxías monosexuais (NELSON, 2006), camiñamos cara a unha educación lingüística pensada como espazo multisexual en que os horizontes de posibilidade e expectativa sexan múltiples e virtuais, no sentido de crearen e aceptaren novos modos que aínda non existan. Nesta dirección, faise imprescindíbel habilitar o que Cynthia Nelson, unha das voces máis relevantes na escrita sobre educación lingüística e teoría queer, denomina "sexual literacy" (NELSON, 2006); ou, noutras palabras, sexualizar a alfabetización. Nun sentido semellante, Paiz di que as identidades sexuais deberían ser centrais na sala de aula e influenciar os procesos de aprendizaxe e adquisición lingüísticas, xa que a queerización ("queering") consistiría en abrir espazos de diálogo e discusión crítica sobre todas as identidades e a súa relevancia sociocultural dun modo respectuoso para todas as identidades e subxectividades (PAIZ, 2019, p. 2).

Estas resalvas, á partida demasiado xerais e pouco aplicábeis ás aulas de linguas, compréndense logo se notamos que as áreas lingüísticas son os espazos pedagóxicos en que máis se teoriza e se tenta levar á práctica a pedagoxía queer, aproveitando o poder da literatura e doutros campos e produtos artísticos, mais tamén da linguaxe como capacidade e ferramenta creativa. Neste sentido, o ideal, do punto de vista de Nelson, sería crear "espazos discursivos queer" que, se ben difíciles, son necesarios mesmo que a escola promova de maneira retórica a inclusión da diversidade e mesmo que xs estudantes mostren unha boa disposición para con estes temas (NELSON, 2006, p. 5). É fácil caer no engano de que abonda con contidos e desvencellarse do importante que é tamén a forma. O caso da sexualidade, desde a perspectiva da quebra do monosexismo e do binarismo de xénero, é explicado por Nelson por medio da súa utilidade no ensino de linguas desde os presupostos da teoría queer: (i) teorizar as identidades sexuais como actos máis do que como factos, (ii) problematizar todas as identidades sexuais antes do que lexitimar as 
subordinadas ou marxinalizadas - o que suporía, como xa indicamos, reforzar o sistema xerárquico e forzar as posibilidades múltiples das sexualidades para encaixaren en identidades sexuais fixas e previamente ordenadas-, (iii) considerar as identidades sexuais como potencialmente significativas para calquera e (iv) atender a como se fai que determinadas identidades sexuais sexan vistas como (a)normais (NELSON, 2002). Todos estes procesos pedagóxicos son intrinsecamente lingüístico-discursivos e susceptíbeis de integrar unha aula de linguas de maneiras diversas e creativas.

\section{PROPOSTAS EN ABERTO DESDE A REFLEXIÓN-ACCIÓN}

Unha vez estabelecido o marco teórico e o procedemento metodolóxico da nosa pesquisa, despois de propor novos modelos de educación lingüística que camiñen cara á experimentación, presentamos algunhas propostas didácticas. Estas deben ser comprendidas como unha proposta máis para enriquecer os materiais didácticos sobre educación afectivo-sexual xa existentes ${ }^{17}$. Máis do que unha intervención estruturada, formulamos ideas en aberto e moi resumidas, que poderán ser flexibilizadas e adaptadas no futuro. Están pensadas para as materias de lingua e literatura das áreas de galego e portugués, polo que sería preciso realizar alteracións eventuais, de maneira a contextualizar as actividades no currículo e até nas referencias socioculturais das distintas variedades e / ou temas.

En primeiro lugar, de acordo ao concepto de "arquivo" que o feminismo contemporáneo ten vindo a reivindicar e a explorar (AHMED, 2010; HALBERSTAM, 2005), temos unha práctica consistente na contaminación crítica do folclore. Os grandes fados clásicos no caso portugués ou as cantigas da música

17 Entre outras, poden consultarse as actividades e propostas didácticas de ARELAS, Asociación de familias de menores trans*: https://asociacionarelas.org/gl/programas/material-didactico/ [última consulta 03/05/2021]. 
e do baile tradicionais galegos son mostras culturais de relacións de xénero e de organización xerárquica do espazo sexual. Coa introdución de discursos alternativos mediante estas prácticas preténdese a ampliación e consciencia crítica dos "repertorios de sentido" do alumnado (MOITA LOPES, 2008, p. 142) ao tempo que se revisita a tradición, xeralmente conceptualizada como unha construción feita sobre fundamentos patriarcais. Un exemplo de partida que poderiamos empregar como mostra para o alumnado é o do grupo lisboeta Fado Bicha ${ }^{18}$. Pensemos, como unha primeira mostra posíbel para a parte galega, na potencia da reescrita feminista e queer de cantigas tradicionais como, por exemplo, "Vaite lavar, porcona!" ou "Apaga o candil" 19. Porén, xunto a ese labor de reescrita tamén habería que pór en valor aquelas producións do repertorio popular que mostran visións alternativas a respecto da diversidade sexo-xenérica (CALLÓN, 2020), así como artistas contemporánexs cuxa actividade revisita a tradición desde perspectivas queer (Alba María, Rodrigo Cuevas, Mercedes Peón, Xisco Feijóo etc.).

En segundo lugar, propomos o estudo do graffiti e da linguaxe pública desde a constancia de que a paisaxe lingüística (PREGO; ZAS, 2018) é tamén unha paisaxe sexual(izada). Neste sentido, é posíbel localizar ideoloxías e asuntos que tocan cuestións de xénero e sexualidade, como mostra o traballo do grupo Galiza Nación Cuir na cidade de Ourense por medio do seu fanzine (GALLEIRA, 2016). Para o noso caso, pensamos na creación dun repositorio dixital en que poidamos pór en común aquelas mostras de paisaxe lingüística

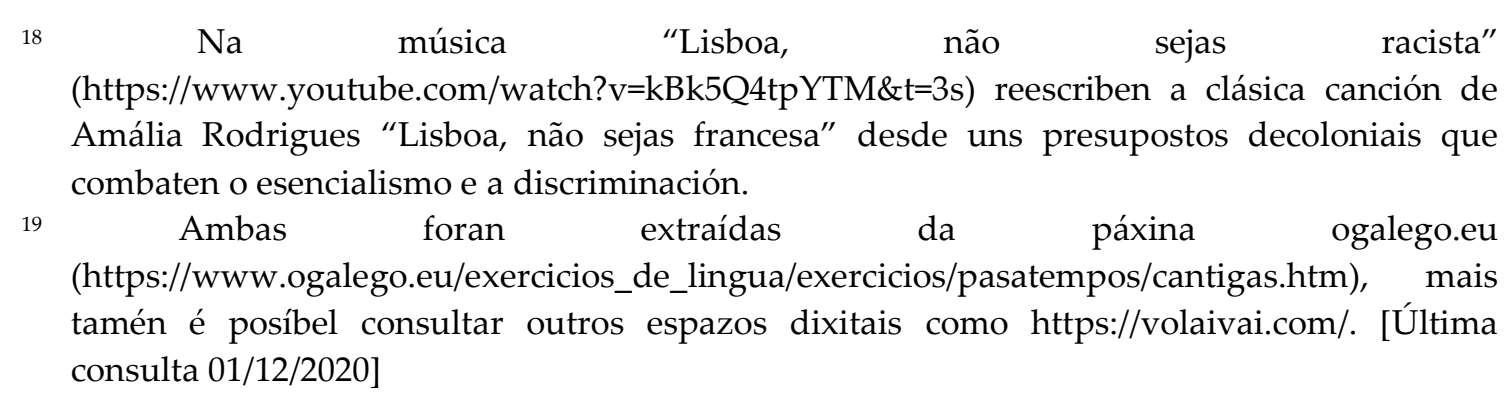


que recollan signos sexuais, quer desde unha perspectiva positiva e emancipadora quer desde unha perspectiva agresora e intimidadora.

En terceiro lugar, temos unha práctica que parte da pedagoxía e reapropiación do insulto (JUNQUEIRA, 2013), que pode ser profundamente suxestiva e transformadora porque reverte os sentidos na interacción discursiva e fai que as persoas marxinadas e asediadas utilicen o poder do insulto dun modo performativo (BUTLER, 2004 [1997]). Consistiría en procurar, nos principais dicionarios para o galego, o español e o portugués, aquelas palabras que usariamos para insultar a alguén con base en cuestións sexuais, comparando os termos e os resultados e explicando - tornando explícito e transparente - o seu sentido despectivo na nosa cultura. Ficar simplemente aí sería insuficiente e vitimista, polo que falariamos tamén sobre como eses insultos se resignifican por parte dos colectivos aos que pretenden ofender. Algúns exemplos poden ser as ocorrencias de "criqueiro/a"20 ("home que ten maneiras efeminadas', sinónimo de maricón) e "maricas"21 ('termo que se utiliza como insulto, co significado de desprezable, ruín, indesexable etc.') no Dicionario da Real Academia Galega; "pederastia"22 ("relación homosexual masculina') no Digalego da Xunta de Galicia; "bollera"23 e "marica"24 no Diccionario de la Real Academia Española; e "paneleiro"25 (paralelamente 'homossexual' e 'fabricante de panelas de barro'), "bicha"26 (paralelamente 'fêmea de animal doméstico', 'pessoa muito irritada', 'homossexual masculino' e 'indivíduo efeminado'), "fufa"27 ('mulher homossexual; lésbica') e

20 https://academia.gal/dicionario/-/termo/criqueiro [última consulta 03/12/2020]

21 https://academia.gal/dicionario/-/termo/maricas [última consulta 03/12/2020]

22 https://digalego.xunta.gal/es/termo/49133/pederastia [última consulta 03/12/2020]

$23 \mathrm{https} / / /$ dle.rae.es/bollero\#5oJdmcb [última consulta 03/12/2020]

24 https://dle.rae.es/marica?m=form [última consulta 03/12/2020]

$25 \mathrm{https} / / / \mathrm{www}$.infopedia.pt/dicionarios/lingua-portuguesa/paneleiro [última consulta 03/12/2020]

$26 \mathrm{https} / /$ www.infopedia.pt/dicionarios/lingua-portuguesa/bicha [última consulta 03/12/2020]

27 https://www.infopedia.pt/dicionarios/lingua-portuguesa/fufa [última consulta 03/12/2020] 
“sapatona"28 (ídem) no Infopédia da Porto Editora. Así, sería posíbel conformar

un pequeno glosario do insulto e chamar a atención para como os colectivos afectados se reapropiaron desa discriminación de modo orixinal.

Por último, propomos un exercicio de creación para as materias de Portugués da ESO. Combinando o traballo de reflexión grupal, de realización de banda deseñada e de dramatización oral, a actividade partiría dunha pequena ficción política interseccional (VIVEROS VIGOYA, 2016):

Existe no norte de Portugal uma aldeia chamada Cuirém, que @s geógraf@s ainda não conseguiram localizar com exatidão. Por muito que tentaram aplicar métodos científicos distintos, este lugar misterioso escapa às lupas de cientistas e, fantasticamente, consegue manter-se a salvo das massas de turistas. Lá não há famílias, mas as pessoas agrupam-se por preferências em pequenas comunidades que podem mudar aos poucos dias. Lá também não existem cárceres, pois quem for malcomportad@terá enfrente o resto de membros e colegas para mostrarem-lhe que existem outros caminhos longe do conflito desnecessário. E, o que é ainda mais importante, ali não há género nem sexualidade: a vizinhança não responde a critérios de homem/mulher, seria impossível identificar se alguém é Maria ou é João porque toda a gente usa nomes distintos. Há Antónios com vagina e Luísas com pénis. Como também é frequente haver nomes que seria difícil ligar a qualquer género, como Cuir, nome da figura que fundou a aldeia. E, claro, não há somente pessoas heterossexuais e homossexuais, cada quem relaciona-se com quem quiser e, às vezes, mesmo muda de gostos.

Porém, há um terrível problema nestes últimos tempos... a despovoação. Cuirém está a ficar sem gente que mantenha esse lugar vivo. É por isso que precisamos enviar uma equipa de pessoas que vá ali para auxiliar na recuperação da aldeia. Como não é possível enviar tod@s vocês, teremos de escolher só um grupo dos X que formarão agora.

Tendo em conta a descrição que acabamos de fazer sobre Cuirém, cada grupo deverá desenhar um plano ou kit, que inclua: um personagem para cada participante com descrições físicas e psicológicas, um labor a fazer na aldeia, um ou vários tipos de relacionamento (ou nenhum) a estabelecer com o resto de colegas do grupo e da aldeia e tudo aquilo que considerarem preciso. Para tal, devem construir uma banda desenhada que dê conta da vossa viagem, com textos escritos integramente em português. Depois, dramatizarão as conversas ao vivo à frente do resto da turma, para escolhermos que equipa será finalmente a enviada.

28 https://www.infopedia.pt/dicionarios/lingua-portuguesa/sapatona

[última consulta 03/12/2020] 
A capacidade de habitar nesta construción imaxinaria, de pensarse e pensar xs outrxs neste espazo (non só xeográfico) e de habitar outros personaxes crean unha comunidade discursiva queer. Animámonos a nós propixs e ao alumnado "a explorar, a envolvernos e a comprender como o xénero é construído na nosa propia presenza na sala de aula"29 (KEDLEY, 2016, p. 115-6), mais tamén aquilo que poderiamos construír imaxinando novas opcións por mecanismos discursivos. Os seus restos visíbeis serán os diálogos ditos ao vivo e en alto polos grupos no pequeno espazo político que é a aula e os debuxos en cadriños da banda deseñada, que conformarían pezas indispensábeis nunha análise posterior desde o modelo pedagóxico que até aquí defendemos.

\section{CONSIDERACIÓNS FINAIS}

No final desta viaxe tomamos consciencia de que, se a escola debería ter o propósito de acoller a existencia (GARCÉS, 2020, p. 27); se a pregunta pola linguaxe é unha interrogación polos modos de vida (FLORES, 2020, p. 90); e se a construción humana do coñecemento está rexistrada na linguaxe e sen esta consciencia non hai comprensión do mundo nin perspectiva crítica (FERNÁNDEZ MARTORELL, 2020, p. 116), cada aula de linguas é un pequeno e vulnerábel corpo cheo de vida e de dúbida. (co-)Existir non é sobrevivir e, xa que logo, a emancipación como proposta docente tense mostrado como un vieiro frutífero para explorar o ensino de linguas desde unha perspectiva abranxente, ultrapasando unha visión da educación lingüística como unha tarefa de regras e gramáticas, onde imperan termos como corrección, dependencia ou afirmación e onde non están presentes termos como vulnerabilidade, incerteza ou pregunta. Fronte a unha

29 "to explore, engage, and understand how gender is constructed in their own presence in the classroom" 
lexibilidade tradicional de tradición patriarcal, as linguas como instrumentos para a experimentación xorden dunha forma desestabilizadora e comunitaria.

Ao longo destas páxinas quixemos, en definitiva, mostrar a posibilidade de introducir modelos pedagóxicos queer nas aulas de linguas como lugares para o xogo e para a (de)construción colectiva por medio de mecanismos precisamente lingüísticos e performativos. Tales estratexias xa están a ser implementadas actualmente por algunhxs docentes ${ }^{30}$, a pesar da frecuencia con que os materiais van na dirección oposta. Por tanto, no final, realizamos as propostas didácticas que ocupan a anterior epígrafe e que visan materializar a utopía e contextualizar a abstracción. Sitúanse no espazo curricular do galego e do portugués, mais cunha forte interacción e un alto grao de intercambio e adaptabilidade. Cremos que é posíbel continuar no futuro por estes camiños de pesquisa e (auto)cuestionamento, porque

[a] posibilidade de activar a imaxinación pedagóxica, de atreverse a imaxinar outros mundos e quebrar coa imaxinación normalizadora, exíxenos outra lingua, comprométenos á ousadía de desarmar os nosos vocabularios pedagóxicos, dun falar en linguas que rache o uso comunicacional da linguaxe que organiza a gramática dominante da escrita docente $^{31}$. (FLORES, 2020, p. 89)

30 No seo deste proxecto investigador, realizamos algunhas entrevistas semidirixidas en profundidade con profesorado de ensino secundario en activo, que por motivos de espazo non son incluídas nesta publicación. Tal profesorado, da área de linguas, indicounos as seguintes prácticas que xa está a desenvolver habitualmente nas súas aulas: debates sobre a linguaxe inclusiva, análise de palabras tabú e eufemismos, comprensión de mecanismos de manipulación na prensa e nos medios, lectura crítica dos exemplos gramaticais encontrados nos distintos materiais, escolla de temas sobre diversidade para traballar o texto argumentativo, construción de glosarios de termos críticos, dramatización de situacións para explicar teoría lingüística (p.e., o acto comunicativo), troca da formación do xénero para a formación do masculino a partir do feminino, análise crítica dos libros de texto por parte do alumnado etc.

Porén, estxs mesmxs docentes critican a falta de apoio e formación por parte das Administracións para o tratamento destes temas e reivindican a creación de redes e equipas maiores e sólidas, na liña do que comenta Trujillo (2015, p. 1538).

31 "[l]a posibilidad de activar la imaginación pedagógica, de atreverse a imaginar otros mundos y romper con la imaginación normalizadora, nos exige otra lengua, nos compromete a la osadía de desarmar nuestros vocabularios pedagógicos, de un hablar en 


\section{REFERENCIAS}

AHMED, Sara. The Promise of Happiness. Durham, NC: Duke University Press, 2010.

APRAIZ JAIO, María Victoria; PÉREZ GÓMEZ, Marimar; RUIZ PÉREZ, Teresa. La enseñanza de las lenguas en la escuela plurilingüe. Revista Iberoamericana de Educación. Madrid, vol. 59, n. 1, p. 119-137, 2012. Dispoñíbel en: [https://rieoei.org/historico/documentos/rie59a05.pdf]. Acceso en: 03/05/2021.

BENGOECHEA BARTOLOMÉ, Mercedes. Lengua y género. Madrid: Síntesis, 2015.

BORBA, Rodrigo. Linguística Queer: uma perspectiva pós-identitária para os estudos da linguagem. Revista Entrelinhas. São Leopoldo (RS), vol. 9, n. 1, p. 91-107, Jan./Jun. 2015.

Dispoñíbel

en:

[http://revistas.unisinos.br/index.php/entrelinhas/article/view/10378]. Acceso en: 27/12/2020.

BRITZMAN, Deborah. La pedagogía transgresora y sus estrañas técnicas. In: MÉRIDA JIMÉNEZ, Rafael M. (ed.). Sexualidades transgresoras. Una antología de estudios queer. Barcelona: Icaria, 2002, p. 197-228.

BRITZMAN, Deborah. ¿Qué es esa cosa llamada amor? In: Pedagogías Trangresoras. Tradución de Gabi Herczeg. Córdoba: bocavulvaria ediciones, 2016, p. 31-65. Dispoñíbel en: [https://www.bibliotecafragmentada.org/wpcontent/uploads/2017/12/PEDAGOGIAS-TRANSGRESORAS-COMPLETO.pdf].

Acceso en: 27/12/2020.

BUTLER, Judith. Lenguaje, poder e identidad. Madrid: Síntesis, 2004 [1997].

BUTLER, Judith. Deshacer el género. Barcelona: Paidós, 2006 [2004].

BUTLER, Judith. El género en disputa. El feminismo y la subversión de la identidad. Barcelona: Paidós, 2007 [1990].

CALLÓN, Carlos. Dez relatos LGBT da narrativa tradicional galega. In: AMARELO, Daniel (coord.). Nós, xs inadaptadxs. Representações, desejos e histórias LGBTIQ na Galiza. Santiago de Compostela: Através, 2020. p. 227-244.

CAMERON, Deborah. Language, Gender and Sexuality: Current Issues and New Directions. Applied Linguistics. Oxford, vol. 26, n. 4, p. 482-502, 2005. Dispoñíbel en: [https://doi.org/10.1093/applin/ami027]. Acceso en: 27/12/2020.

CAMERON, Deborah; KULICK, Don. Language and sexuality. Cambridge: Cambridge University Press, 2003.

CARRERA FERNÁNDEZ, María Victoria; CID-FERNÁNDEZ, Xosé Manuel; LAMEIRAS FERNÁNDEZ, María. El status queer o la utopía de lo posible: aportaciones de la pedagogía queer para la construcción de nuevos imaginarios

lenguas que fisure el uso comunicacional del lenguaje que organiza la gramática dominante de la escritura docente" 
identitarios. In: OCAMPO GONZÁLEZ, Aldo (coord.). Pedagogías Queer. Santiago de Chile: CELEI, 2018. p. 48-70.

DEPALMA, Renée. O proxecto No Outsiders: de-construír a heteronormatividade en centros educativos, 2017. Dispoñíbel en: [https://www.academia.edu/34398015/O_proxecto_No_Outsiders_-_Deconstrui_r_a_heteronormatividade_en_centros_educativos]. Acceso en: 27/12/2020.

DIGALEGO. Dicionario de galego. Santiago de Compostela: Ir Indo Edicións; Xunta de Galicia. Dispoñíbel en: [https://digalego.xunta.gal/]. Acceso en: 03/12/2020.

DICIONÁRIO INFOPÉDIA DA LÍNGUA PORTUGUESA [em linha]. Porto: Porto Editora, 2003-2020. Dispoñíbel en: [https://www.infopedia.pt/dicionarios/linguaportuguesa]. Acceso en: 03/12/2020.

EHRLICH, Susan; MEYERHOFF, Miriam; HOLMES, Janet (eds.). The Handbook of Language, Gender and Sexuality. Oxford: Wiley Blackwell, 2017.

EPSTEIN, Debbie; JOHNSON, Richard. Schooling Sexualities. Buckingham: Open University Press, 1998.

FERNÁNDEZ MARTORELL, Concha. Observaciones a la retórica de las nuevas propuestas pedagógicas. In: GARCÉS, Marina et al. Pedagogías y emancipación. Barcelona: Arcàdia / MACBA, 2020, p. 99-127.

FLORES, Valeria. Entre secretos y silencios. La ignorancia como política de conocimiento y práctica de (hetero)normalización. Revista Trabajo Social. Ciudad de México, n. 18, p. 14-21, $2008 . \quad$ Dispoñíbel en: [http://www.revistas.unam.mx/index.php/ents/article/view/19514]. Acceso en: 26/12/2020.

FLORES, val. Afectos, pedagogías, infancias y heteronormatividad. Reflexiones sobre el daño. In: Pedagogías Trangresoras. Córdoba: bocavulvaria ediciones, 2016, p. 13-30. Dispoñíbel en: [https://www.bibliotecafragmentada.org/wpcontent/uploads/2017/12/PEDAGOGIAS-TRANSGRESORAS-COMPLETO.pdf].

Acceso en: 26/12/2020.

FLORES, val. Activaciones poéticas de la disidencia. Un hiato pedagógico para criar una lengua emancipatoria. In: GARCÉs, Marina et al. Pedagogías y emancipación. Barcelona: Arcàdia / MACBA, 2020. p. 77-98.

FRA [European Union Agency for Fundamental Rights]. A long way to go for LGBTI equality. Viena: FRA, 2020a. Dispoñíbel en: [https://fra.europa.eu/sites/default/files/fra_uploads/fra-2020-lgbti-equality_en.pdf]. Acceso en: 15/11/2020.

FRA [European Union Agency for Fundamental Rights]. European Union lesbian, gay, bisexual and transgender survey. Results at a glance. Viena: FRA, 2020b. Dispoñíbel en: [https://fra.europa.eu/sites/default/files/eu-lgbt-survey-results-at-a-glance_en.pdf]. Acceso en: 15/11/2020.

FRANCISCO AMAT, Andrea; AGUIRRE GARCÍA-CARPINTERO, Arecia; MOLINER MIRAVET, Lidón. Heterosexual, ¿qué es eso? Percepciones sobre identidades sexuales 
en educación secundaria. Revista de Investigación Educativa. Murcia, vol. 36, n. 1, p. 93108, 2018. Dispoñíbel en: [https://doi.org/10.6018/rie.36.1.289241]. Acceso en: $18 / 11 / 2020$.

GALLEIRA, A. Comisión de Sexo-diversidade. Galiza Nación Cuir (fanzine). N. 0, 2016. Dispoñíbel en: [https://es.calameo.com/read/0047925661cc2d1470f67]. Acceso en: 22/12/2020.

GARCÉS, Marina. El contratiempo de la emancipación. In GARCÉS, Marina et al. Pedagogías y emancipación. Barcelona: Arcadia / MACBA, 2020. p. 21-47.

GRECO, Luca. Production, circulation and deconstruction of gender norms in LGBTQ speech practices. Discourse Studies. [S.l.], vol. 14, n. 5, p. 567-85, 2012. Dispoñíbel en: [https://doi.org/10.1177\%2F1461445612452229]. Acceso en: 27/12/2020.

HALBERSTAM, J. Jack. In a Queer Time and Place: Transgender Bodies, Subcultural Lives. Nova York: New York University Press, 2005.

HOOKS, bell. Teaching to Transgress. Education as the Practice of Freedom. Nova York: Routledge, 1994.

JUNQUEIRA, Rogério Diniz. Pedagogía del armario. La normatividad en acción. Retratos de la Escuela. Brasília, vol. 7, n. 13, p. 481-98, 2013. Dispoñíbel en: [https://doi.org/10.22420/rde.v7i13.349]. Acceso en: 22/12/2020.

KEDLEY, Kate E. The Teacher as a Text: Un-centering Normative Gender Identities in the Secondary English Language Arts Classroom. In: MILLER, sj (ed.). Teaching, Affirming, and Recognizing Trans and Gender Creative Youth. A Queer Literacy Framework. Nova York: Palgrave Macmillan, 2016. p. 107-19.

KJARAN, Jón Ingvar. Constructing Sexualities and Gendered Bodies in School Spaces. Nordic Insights on Queer and Transgender Students. Nova York: Palgrave Macmillan, 2017.

LEAP, William. Word's Out: Gay Men's English. Minneapolis: University of Minnesota Press, 1996.

LIVIA, Anna; HALL, Kira (eds.). Queerly Phrased. Nova York: Oxford University Press, 1997.

LOURO, Guacira Lopes. Pedagogias da sexualidade. In: LOPES LOURO, Guacira (org.). O corpo educado. Belo Horizonte: Autêntica, 2000. p. 7-34.

LOURO, Guacira Lopes. Teoria queer - uma política pós-identitária para a educação. Estudos Feministas. Florianópolis, vol. 9, n. 2, p. 541-53, 2001.

LUHMANN, Susanne. Queering/Querying Pedagogy? Or Pedagogy Is a Pretty Queer Thing. In: PINAR, William (ed.). Queer Theory in Education. Mahwah / New Jersey / Londres: LEA, 1998. p. 120-132.

MORENO SÁNCHEZ, José Javier. Lingüística Queer y Análisis Crítico del Discurso. Aplicaciones en el ámbito educativo. In: CUTILLAS ORGILÉS, Ernesto (ed.). La multiplicidad de enfoques en Humanidades. Actas de las VIII Jornadas de Investigación de la 
Facultad de Filosofía y Letras de la Universidad de Alicante (Alicante, 3 y 4 de mayo de 2018). Alicante: Facultad de Filosofía y Letras de la Universidad de Alicante, 2019. p. 53-9.

MENARD-WARWICK, Julia; MORI, Miki; WILLIAMS, Serena. Language and Gender in Educational Contexts. In: EHRLICH, Susan; MEYERHOFF, Miriam; HOLMES, Janet (eds.). The Handbook of Language, Gender and Sexuality. Oxford: Wiley Blackwell, 2017. p. 471-90.

MILANI, Tommaso M. Expanding the Queer Linguistic scene. Multimodality, space and sexuality at a South African university. Journal of Language and Sexuality. [S.l.], vol. 2, n. 2, p. 206-34, 2013. Dispoñíbel en: [https://doi.org/10.1075/jls.2.2.02mil]. Acceso en: 26/12/2020.

MOITA LOPES, Luiz Paulo da. Identidades fragmentadas: a construção discursiva de raça, gênero e sexualidade em sala de aula. Campinas: Mercado de Letras, 2006.

MOITA LOPES, Luiz Paulo da. Sexualidades em sala de aula: discurso, desejo e teoria queer. In: MOREIRA, Antonio Flávio; CANDAU, Vera Maria (orgs.). Multiculturalismo. Diferenças Culturais e Prácticas Pedagógicas. Petrópolis: Vozes, 2008. p. 125-48.

NELSON, Cynthia D. Why Queer Theory Is Useful in Teaching: A Perspective from English as a Second Language Teaching. Journal of Gay E Lesbian Social Services. [S.l.], vol. 14, n. 2, p. 43-53, 2002. Dispoñíbel en: [https://doi.org/10.1300/J041v14n02_04]. Acceso en: 20/12/2020.

PAIZ, Joshua M. Queering Practice: LGBTQ+ Diversity and Inclusion in English Language Teaching. Journal of Language, Identity \& Education. [S.l.], vol. 18, n. 4, 2019. Dispoñíbel en: [https://doi.org/10.1080/15348458.2019.1629933. Acceso en: 20/12/2020.

PLANELLA, Jordi; PIE, Asun. Pedagoqueer: resistencias y subversiones educativas. Educación XXI. [S.l.], vol. 15, n. 1, p. 265-83, 2012. Dispoñíbel en: [https://doi.org/10.5944/educxx1.15.1.159]. Acceso en: 22/12/2020.

PLATERO, Lucas. Ideas clave de las pedagogías transformadoras. In: OCAMPO GONZÁLEZ, Aldo (coord.). Pedagogías Queer. Santiago de Chile: CELEI, 2018, p. 26-46.

PREGO VÁZQUEZ, Gabriela; ZAS VARELA, Luz. Paisaje lingüístico. Un recurso TIC, TAC, TEP para el aula. Lingue Linguaggi. Salento, vol. 25, p. 277-95, 2018. Dispoñíbel en: [http://siba-ese.unisalento.it/index.php/linguelinguaggi/article/view/18952]. Acceso en: 19/11/2020.

REAL ACADEMIA ESPAÑOLA. Diccionario de la lengua española, 23. a ed., [versión 23.4 en línea]. Dispoñíbel en: [https://dle.rae.es]. Acceso en: 03/12/2020.

REAL ACADEMIA GALEGA. Dicionario da Real Academia Galega. Dir. Manuel González González. 2012. Dispoñíbel en: [https://academia.gal/dicionario]. Acceso en: 03/12/2020.

SANTOS FILHO, Ismar Inácio dos Santos. Linguística queer - para além da língua(gem) como expressão do lugar do falante. In: SILVA, António de Pádua Dias da (org.). Escrit@s sobre gênero e sexualidade. São Paulo: Scortecci, 2015. p. 15-28. 
SEDGWICK, Eve Kosofsky. Epistemologia do Armário. Coimbra: Angelus Novus, 2003 [1990].

TRUJILLO, Gracia. Pensar desde otro lugar, pensar lo impensable: hacia una pedagogía queer. Educação e Pesquisa. São Paulo, vol. 41, p. 1527-40, Dec. 2015. Dispoñíbel en: [http://dx.doi.org/10.1590/S1517-9702201508142550]. Acceso en: 02/12/2020.

VIVEROS VIGOYA, Mara. La interseccionalidad: una aproximación situada a la dominación. Debate Feminista. Ciudad de México, vol. 52, p. 1-17, 2016. Dispoñíbel en: [https://doi.org/10.1016/j.df.2016.09.005]. Acceso en: 27/12/2020.

XUNTA DE GALICIA. Guía da LOMCE, s/d. Dispoñíbel en: [https://www.edu.xunta.gal/portal/guiadalomce]. Acceso en: 20/12/2020.

Nota do editor:

Artigo submetido para avaliação em: 28 de dezembro de 2020.

Aprovado em sistema duplo cego em: 05 de maio de 2021. 